\title{
La ciudadanía en cuestión: una aproximación etnográfica a los usos policiales de la fuerza y la conformación de colectivos contra la violencia policial The citizenship in question: an ethnographic approximation to the police uses of force and the conformation of groups against the police violence
}

\section{Nicolás Barrera}

Nicolás Barrera se desempeña en la Escuela de Antropología, Facultad de Humanidades y Artes, Universidad Nacional de Rosario, Argentina.

E-mail: nicbarrera@hotmail.com

\section{resumen}

A lo largo de casi dos años, entre 2010 y 2011, hicimos trabajo de campo antropológico en distintas dependencias policiales de la ciudad de Rosario pertenecientes a la Unidad Regional II de la policía de la provincia de Santa Fe. Allí, además de realizar observaciones, entrevistamos a funcionarios policiales con destino en sus dos principales agrupamientos: Comando Radioeléctrico y comisarías. Sobre la base del material etnográfico elaborado durante ese período y de numerosas entrevistas realizadas paralelamente con familiares de víctimas de violencia policial, en este artículo en particular nos proponemos reflexionar relacionalmente sobre las múltiples significaciones y apelaciones a la ciudadanía que se expresan en un contexto caracterizado por prácticas policiales que, según entendemos, asumen un carácter marcadamente territorial y discrecional.

\section{palabras clave}

ciudadanía / usos policiales de la fuerza / movimientos sociales

\section{summary}

Over nearly two years, between 2010 and 2011, we did anthropological fieldwork in various police dependences in the city of Rosario, wich belongs to the Police's Regional Unit $\mathrm{N}^{\circ} 2$ in the province of Santa Fe. There, in addition to observations, we interviewed police officers stationed in its two main groupings: "Comando Radioeléctrico" and "comisarías". Based on ethnographic material produced during that period and numerous parallel interviews with relatives of victims of police violence, in this article in particular we propose to reflect on the many meanings of citizenship that are expressed in a context marked by police practices that assume a territorial and discretional character. keywords

citizenship / police use of force / social movements 
"Mi primera reacción fue estar firme. Yo cuando dejo a mi hijo en el cementerio y llego a mi casa... eh.... me desperté y dije 'no, yo tengo que hacer algo, a mí no me pueden venir a arrebatar un hijo así porque sí y quedar en... en la nada'. Y es ahí cuando empiezo... a la semana hago la primera marcha a... a Jefatura".

"Aunque, para llegar a algo tuvimos que caminar mucho, en estos dos años, aprendimos que tenemos nuestros derechos. Aprendimos a ponernos firmes" (www.enredando.org, 29/07/05).

\section{Introducción}

"Yo tengo que hacer algo, a mí no me pueden venir a arrebatar un hijo así porque sí y quedar en... en la nada". Una percepción, un saber que supone que hay determinados hechos que no pueden ocurrir porque sí, arbitrarios, sin sentido, aparece con contundencia en el relato de la madre que acaba de perder a su hijo. Un sentido que reconoce la portación de determinados derechos y que, más allá de su aparente espontaneidad, constituye un concepto de gran profundidad histórica relacionado, ya sea directa o indirectamente, con el desarrollo de la noción de ciudadanía. Ahora bien, no obstante la densidad histórica de este concepto, es en las últimas décadas cuando se ha revitalizado su apelación a partir de los impactos recesivos que han tenido sobre todo las políticas neoliberales y los programas de ajuste sobre las condiciones de ciudadanía en amplios sectores de la sociedad argentina.

Si bien las alusiones más inmediatas remiten al estatus jurídico y a la pertenencia a una comunidad política (a derechos y obligaciones proyectados como "universales"), relatos como el que reproducimos presuponen una noción de ciudadanía en tanto experiencia multidimensional que involucra, además de las dimensiones señaladas, un conjunto amplio de identificaciones, acciones e ideas que se construyen en la vida cotidiana y que posicionan a los sujetos sociales frente a sí mismos, frente a otros y de cara al Estado (Bloj, 2008).

En este sentido, en sociedades complejas y diversificadas como la argentina, donde los principios de igualdad ante la ley conviven con relaciones fuertemente jerarquizadas ${ }^{1}$, las prácticas de ciudadanía en tanto conjunto de identificaciones, acciones y representaciones, expresan procesos de disputa en torno a su misma definición y sus diferentes modos de legitimación.

Así es que en este artículo en particular nos proponemos reflexionar sobre las múltiples significaciones que expresan las distintas apelaciones a la ciudadanía, a partir de un campo de estudio delimitado por la emergencia de prácticas policiales violentas que culminan con la muerte de la víctima. En el mismo, se manifestarán las tensiones propias de un escenario donde nos encontramos con modos estandarizados del accionar policial que fundamentan la utilización de la fuerza en forma discrecional, negando condiciones de ciudadanía para poblaciones territorialmente localizadas, al mismo tiempo que con el surgimiento de sujetos, movimientos y organizaciones que reclaman justicia ante este tipo de hechos, en tanto experiencias articuladas alrededor de la búsqueda de construcción de ciudadanía. 
Esta tensión será debatida a lo largo del artículo asumiendo un enfoque etnográfico que parte de observaciones hechas en distintas comisarías y, principalmente, de entrevistas realizadas tanto a personal policial jerárquico como subalterno con destino en comisarías y Comando Radioeléctrico de la ciudad de Rosario. Dicho material etnográfico forma parte de una investigación antropológica mayor ${ }^{2}$ en la cual tuvimos la oportunidad de entrevistar a siete comisarios, tres subcomisarios, cinco oficiales y catorce agentes, así como de permanecer durante varios meses realizando observaciones en 7 comisarías, seleccionadas por su representatividad de los diferentes distritos y zonas que conforman la ciudad.

El acceso a un campo que aparece muchas veces impermeable a una mirada externa y que incluso ha sido en ciertos momentos definido por algunos investigadores como "opaco", fue posible gracias a la colaboración de los funcionarios políticos que en ese momento ${ }^{4}$ se encontraban a cargo del Ministerio de Seguridad de la provincia de Santa $\mathrm{Fe}^{5}$, quienes en todo momento mostraron su receptividad y colaboración para facilitar el desarrollo de la investigación.

Asimismo, y siguiendo en esto los lineamientos del enfoque relacional (Menéndez, 2002, 2010; Bourdieu y Wacquant 1995), complementan el material etnográfico las entrevistas realizadas a familiares de las víctimas de violencia policial nucleados en la agrupación "Padres del Dolor". El acceso a las mismas se dio gracias a la gentileza y predisposición de Gladis Gauna, quien ofició como contacto y nexo con las madres organizadas en dicha agrupación.

Todas las entrevistas fueron realizadas en el lugar de trabajo para el caso de los policías y en domicilios particulares para el caso de familiares, lugares en los que además fueron registradas diversas situaciones de campo que quedaron asentadas en observaciones inscritas en el "diario de campo".

\section{Ciudadanía}

"Para llegar a algo tuvimos que caminar mucho, en estos dos años, aprendimos que tenemos nuestros derechos. Aprendimos a ponernos firmes". El concepto y las condiciones de ciudadanía no constituyen una propiedad o un estatus definido, tratan en todo caso de un proceso, una construcción y en tanto construcción han sido objeto de diferentes reflexiones de las cuales el campo de las ciencias sociales no ha sido ajeno. No obstante, emprender este recorrido desde la antropología en particular presenta dificultades específicas ya que se trata de un campo que no forma parte del objeto de estudio tradicional de nuestra disciplina. La ciudadanía:

"en tanto categoría intrínsecamente ligada a la constitución del Estado moderno es posible agruparla junto con otras macro-categorías que han caído fuera de los intereses clásicos de la disciplina (las sociedades "sin estado"); también por la escala que excedería las posibilidades metodológicas. Los primeros acercamientos explícitos se producen luego de la Segunda Guerra Mundial y alrededor de cuestiones como la identidad nacional, la nación y nacionalismos; fenómenos que habían sido desplazados hasta ese momento por sus evocaciones al fascismo" (Bloj 2008: 34). 
Entre las formas en que históricamente fue pensada la ciudadanía resulta ineludible la referencia a la tipología elaborada por T. H. Marshall. En "Ciudadanía y Clase Social" (2004), preocupado fundamentalmente por los contenidos de los derechos ciudadanos y su expansión histórica (Jelin, 2003), Marshall establece una división de la ciudadanía en tres partes: la civil, la política y la social. Los componentes civiles estarían conformados por los derechos necesarios para la libertad individual de las personas, la libertad de palabra, pensamiento y credo, el derecho a la propiedad y a la justicia. Los elementos que componen la ciudadanía política estarían representados por el derecho a participar en el ejercicio del poder político, en tanto miembro de un organismo dotado de autoridad política o como elector de sus miembros. Mientras que dentro de los componentes sociales de la ciudadanía, Marshall incluye toda la variedad contenida en el espectro que va desde el derecho a una medida de seguridad y bienestar económico hasta el derecho a compartir la herencia social. Marshall encuentra una relación evolutiva y cronológica entre los tres que, aunque flexible, se expresaría, siguiendo el modelo inglés, en el desarrollo de los derechos civiles en el siglo XVIII, los políticos en el siglo XIX y los sociales en el XX.

Esta clasificación dio lugar a pensar los derechos humanos en términos de derechos de primera, segunda y tercera generación. Los derechos civiles y políticos, consagrados en los ordenamientos jurídicos nacionales e internacionales, representarían los derechos humanos de primera generación y estarían destinados a la protección del ser humano individualmente considerado contra cualquier agresión del Estado. Por su parte, los derechos económicos, sociales y culturales, que refieren al derecho al trabajo, a la educación, a la salud, a la protección y asistencia de niños, niñas y adolescentes, a la familia y a la vivienda, requiriendo de la actuación del Estado para garantizar que todos puedan tener acceso a estos derechos, representarían los derechos humanos de segunda generación. Y por último, a estas dos generaciones de derechos, ya previstas en la clasificación de Marshall, se agregaría una tercera que refiere a los derechos de los pueblos: derecho al desarrollo, a la libre determinación, al medio ambiente, a la paz (Di Marco et al., 2005).

Ya ha sido suficientemente cuestionada -desde una perspectiva latinoamericana que denuncia el eurocentrismo del modelo de Marshall- la linealidad de esta progresión, fundamentalmente a partir de encontrarnos con situaciones y procesos históricos en los que estos campos se entrecruzan. Entre estos cuestionamientos, se destaca el trabajo de Elizabeth Jelin $(1996,2003)$ quien ha demostrado, por ejemplo, cómo en el contexto latinoamericano del siglo XX la expansión de derechos sociales no siempre fue acompañada por una expansión de los derechos civiles y políticos, y mucho menos fue su consecuencia.

La no linealidad de este desarrollo en el caso latinoamericano se termina expresando en un hecho que resulta paradójico: el reconocimiento de gran parte de estos derechos se da en un contexto de políticas neoliberales que genera al mismo tiempo un fuerte proceso de exclusión, el cual limita los posibles alcances de la ciudadanía. En este sentido es que Manuel Garretón (2006) señala que en Latinoamérica: 
“... el fenómeno de expansión de la aspiración ciudadana es cruzado y redefinido por la exclusión de vastos sectores que pueden llegar a dos tercios de una sociedad. Los tipos y formas de exclusión son muy diversos y están referidos tanto a los ámbitos clásicos de la ciudadanía, como sobre todo a los nuevos ya mencionados y que definen los modelos de modernidad" (2006: 53).

Se trata de una paradoja que, aunque irresoluble, expone la complejidad del fenómeno. La misma cristaliza claramente en un proceso que al mismo tiempo que reconoce y amplía derechos puede también negarlos. Ahora bien, tal paradoja parece desvanecerse en el campo del que partimos para nuestro análisis, donde la letalidad en la utilización de la fuerza por parte de la policía aparenta negarla de raíz. En esos casos, los diferentes grados de desarrollo de la ciudadanía, sus logros, sus avances y sus retrocesos, se esfuman en un solo acto. Allí, lo que era un sujeto de derechos trasmuta en un objeto; en nombres que, entre los más afortunados, pasan a titular voluminosos expedientes.

No obstante lo cual, la paradoja no desaparece. El mismo contexto que puede negar condiciones de ciudadanía, se constituye en una oportunidad para que aquellos que se consideran víctimas de estos procesos, vuelvan visible su posición. En este sentido es que algunos autores han resaltado que el escenario representado por el neoliberalismo ha servido también para cuestionar la idea de ciudadanía universal que considera al ciudadano como un individuo libre, sujeto de derechos y obligaciones, para dar lugar a plantear formas particulares de derechos universales como, por ejemplo, las "ciudadanías diferenciadas" (Di Marco et al., 2005) que, partiendo de las diferencias socioculturales, enfatiza el derecho de determinados grupos poblacionales (mujeres, niños, indígenas, etc.) a ser reconocidos por su propia identidad. Y si bien las prácticas de quienes cuestionan la violencia policial no pueden englobarse bajo las formas de recrear ciudadanía propia de estos nuevos grupos identitarios, comparten al menos una misma problematización de los principios abstractos de igualdad contenidos en la idea de la ciudadanía, a la vez que propugnan, al mismo tiempo, una reconfiguración de los sujetos que claman ("que aprenden a ponerse firmes") por sus condiciones de ciudadanía.

Es nuestra intención discutir este nuevo escenario asumiendo un enfoque etnográfico y relacional que reflexione sobre la problemática en forma situacional, a partir de procesos y experiencias concretas. Puntualmente, como ya venimos adelantando, nos interesan los derivados de la utilización discrecional de la fuerza por parte de la policía provincial en la ciudad de Rosario.

\section{Usos discrecionales de la fuerza}

"Yo cuando dejo a mi hijo en el cementerio y llego a mi casa... eh.... me desperté y dije 'no, yo tengo que hacer algo, a mí no me pueden venir a arrebatar un hijo así porque sí y quedar en... en la nada". Las formas de construcción de ciudadanía que nos proponemos analizar emergen de una ruptura. Un corte abrupto en una cadena de situaciones cotidianas propias de la actividad policial. Un momento puntual en el que el arma reglamentaria es disparada y asesina a un civil, un delincuente para 
algunos, un ciudadano para otros. Se trata de una disputa de sentido que esconde detrás un ciclo que se abre no en el acto de empuñar el arma, no en la decisión brutal de utilización de la fuerza, sino en un cúmulo de prácticas rutinizadas, de valores y representaciones naturalizados, de formas de sentir y vivir el ser policía que se expresan, transitan, se contradicen, se niegan, en el marco de las prácticas policiales. Una ruptura que sintetiza, reactualiza y exterioriza a las prácticas policiales violentas en tanto procesos de negación de la ciudadanía.

Para dimensionar las manifestaciones empíricas de esta articulación recurrimos a un relevamiento de fuentes periodísticas ${ }^{6}$ el cual nos permite establecer que entre los años 2002 y 2010 se sucedieron 72 casos de violencia que culminaron con la muerte de la víctima ${ }^{7}$ y en los que intervinieron funcionarios -en ejercicio o retirados ${ }^{8}-$ de la policía provincial. Se trata de hechos de violencia que culminan en muerte de civiles y que pueden tratarse ya sea de enfrentamientos, ejecuciones, muertes provocadas en operativos de control, en el marco de protestas sociales o uso de la fuerza por motivos particulares, quedando por fuera de este relevamiento solamente las muertes ocurridas bajo custodia.

A partir de este relevamiento, comenzamos a observar que el espacio constituía una de las principales dimensiones modeladoras del accionar policial a partir de inferir una cierta discrecionalidad territorial ${ }^{9}$ en las posibilidades de utilización de la fuerza, que se manifestaba, sobre todo, en el hecho de que estas prácticas se suceden fundamentalmente por fuera del radio del macrocentro rosarino (comisarías $1^{\circ}, 2^{\circ}$ y $3^{\circ}$ ) y de barrios tradicionales de sectores medios y altos (comisarías $4^{\circ}$ a $10^{\circ}$ ) -exceptuando solamente ocho casos, lo cual representa una cifra cercana al 10\% del total- concentrándose en zonas cercanas a asentamientos o viviendas sociales FONAVI.

Desde la clásica monografía de Evans Pritchard sobre los Nuer (1992), la antropología ha reflexionado sobre el problema del espacio y el territorio sin limitarse a las características que emergen del ambiente físico. En dicho texto, Evans Pritchard distingue entre la distancia ecológica que está basada en una relación entre comunidades definida en función de la densidad y de la distribución, y en relación con el agua, la vegetación, la vida animal, los insectos, etc. y la distancia estructural que va a definir la distancia entre grupos de personas en un sistema social, expresada en función de los valores.

Más tarde, Pierre Bourdieu (1999) retomará esta distinción con el objetivo de problematizar el pensamiento sustancialista acerca de determinados lugares. Así, al momento de analizar el "gueto" o los "suburbios problemáticos", Bourdieu distingue entre el espacio físico y el espacio social. En el planteo de Bourdieu, la incorporación de las estructuras del orden social se hace efectiva, en gran medida, a través de la experiencia prolongada e indefinidamente repetida de las distancias espaciales sobre las cuales se afirman determinadas distancias sociales. Bourdieu nos está planteando, de esta manera, una trayectoria en la que las estructuras sociales convertidas en estructuras espaciales, y con ello naturalizadas, vuelven evidente al espacio como uno de los lugares donde se afirma y ejerce el poder. 
Sobre esta base, gran parte de los trabajos actuales que desde nuestra disciplina se van a plantear el problema de la territorialidad (Reguillo, 2008; Barabas, 2005, García Canclini, 1994), parten de entenderla en forma directamente relacionada con el modo en que los sujetos conciben, significan y clasifican un espacio determinado, en el marco de luchas por su apropiación tanto material como simbólica. En este sentido es que, por ejemplo, Rita Segato (2007) entiende al territorio como un espacio representado y apropiado:

"territorio es siempre representación social del espacio, espacio fijado y espacio de fijación vinculado a entidades sociológicas, unidades políticas, órganos de administración, y a la acción, y existencia de sujetos individuales y colectivos (...). Territorio es espacio apropiado, trazado, recorrido, delimitado" (2007: 72).

Entre los policías rosarinos, las estrechas relaciones entre el espacio físico y el espacio representado forman parte de la dinámica de trabajo cotidiana. Ello se expresa, por ejemplo, al momento de representarse las seccionales policiales y las dependencias administrativas correspondientes, donde, lejos de corresponderse con la división jurisdiccional normativa, emerge recurrentemente una primera y gran oposición entre "comisarías del centro" y "comisarías barriales" o "de trabajo".

Se plantea así una primera gran diferenciación que no emerge necesariamente de las condiciones ambientales de trabajo (si bien éstas influyen claramente) sino más bien del arco de relaciones sociales que cada jurisdicción implica para la policía. Tal sentido es planteado por Carrasco ${ }^{10}$, suboficial perteneciente a una comisaría de la zona noroeste:

"Las comisarías, inclusive dentro de lo que es mismo la organización, el organigrama de una comisaría o el desempeño de una comisaría es distinto, de una 'comisaría de centro' a una 'comisaría de villa', como decimos nosotros o... 'comisaría de trabajo' como se le dice. Las comisarías de centro trabajan otras cosas, trabajan con jueces, con abogados y eso mismo te... digamos, como que te apropiás ese trato y con tus mismos compañeros. En una comisaría de acá, donde estamos constantemente ocupados (...), constantemente en laburo, es otra cosa...".

No obstante, tal como se desprende de esta cita, parece existir un elemento objetivo que sirve como parámetro para clasificar a una jurisdicción ya sea como "céntrica" o bien como "de trabajo", que consiste básicamente en la presencia o ausencia de villas de emergencia al interior de su perímetro. Fernández, subjefe de una dependencia de la zona sur nos manifestaba en ese sentido:

"Sí, hay particularidades, porque por ejemplo, la comisaría X es muy escaso los asentamientos precarios que tenemos, tenemos lo parte, parte de lo que sería eh la Villa L, que dentro de todo lo fueron remodelando, fueron sacando gente y quedó un poco menos, o sea estando en la Y nos encontrábamos con un 50 o $60 \%$ de asentamiento, entonces son otras, otros modos de trabajar, o sea todo, todo tiene un modo de trabajar, para todo hay que usar criterios, porque no podemos usar un criterio para trabajar por ahí lo que sería una comisaría X con la gente que se encuentra ahí, o con la 
persona que se encuentra ahí, con trabajar con las personas que están en el asentamiento".

Se trata de sentidos a partir de los cuales se conceptualiza el territorio que trascienden los límites de una jurisdicción particular, y caracterizan la forma de discriminar el trabajo y clasificar en consecuencia el carácter de una comisaría, definiendo además los criterios pertinentes de actuación.

Al mismo tiempo, esa representación negativa del territorio asociada a la presencia de villas en la jurisdicción es compartida también por funcionarios que tienen como destino el Comando Radioeléctrico. En este caso, la misma se da, principalmente, con referencia al mundo de los "pasillos". ${ }^{11} \mathrm{El}$ pasillo siempre es vinculado a la idea de 'acción'. Gagliardi, sumariante ${ }^{12}$ de la misma comisaría de zona noroeste pero con trayectoria también en Comando, nos decía:

"Me gusta lo que sería la parte de acción... llega en móvil, llega un móvil, llegan dos móviles, bueno, se, se trata de, de localizar al, al autor del hecho, nos metemos, nos metíamos en los pasillos, si teníamos salíamos, qué se yo algo, peleando con todo el mundo porque se nos colgaban todo el mundo las mujeres, chicos, porque peleabas hasta con los perros que se te cruzan...".

Los pasillos aparecen, para el personal de ambas dependencias, no sólo como territorios físicos sino como espacios cargados de imágenes que semejan un campo de batalla. Pereyra, agente con larga trayectoria en el interior de la fuerza afirmaba:

"Entonces suponete te largás vos, o se larga tu compañero a correr a alguno, pero por la noche no te podés largar, podés caer en las trampas, pisar un alambre, que te están esperando atrás de las paredes o detrás de las puertas, te esperan mismo detrás y te, te, te disparan de... por la espalda. Muchas veces hemos entrado a los pasillos y nos han, nos hemos encontrado con alambres de púas cruzados en los pasillos, vos venís corriendo de noche y no lo ves... sacaste el arma y te matan...".

El mundo de los pasillos - ese territorio que va representándose sobre una relación de exterioridad radical con respecto al radio de acción de la policía- aparece también como un territorio donde la violencia emerge transparente. El sumariante de zona noroeste que citábamos anteriormente -el que a pesar de su función administrativa manifestaba vocación por la función policial preventiva- nos decía que:

"se complica mucho patrullar... estábamos y siento chiflidos así... saco

el arma y no sabía para donde disparar... porque más siendo en una villa te sale gente de todos lados..."; para contextualizar más adelante dichas escenas en territorios precisos: "en esas zonas conflictivas que te marqué ahí, hay pasillos por todos lados, no sabés lo que te puede salir”.

Las formas de representación del territorio están, al mismo tiempo, atravesadas y ratificadas por una mirada institucional. Así, el modo de concebir el espacio ocupado por asentamientos irregulares se expresa inclusive en el mapa de la ciudad con el que trabaja el GPS de la central del Comando Radioeléctrico y del 911. En el mismo estos territorios aparecen remarcados con color amarillo. En este sentido, uno de los operadores más experimentados nos señalaba que el mapa: 
"Te permite mapear ciertas cuestiones, nosotros vamos cargando información, por ejemplo el espacio que dejo en verde es sector parquizado, el sector en amarillo son villas de emergencia, ¿está? Tenés las comisarías marcadas, después si vos querés seguir entrando en el programa te permite ver donde están todas las escuelas, los hospitales, donde están todos los bancos, o sea, es toda información que vos podés ir mapeando sobre algo ya preestablecido que es el mapa de la ciudad de Rosario (...). Lo que sí tenemos fijo es eso, lo que son espacios verdes, más allá de todo lo que sean las calles, avenidas, y el ferrocarril porque ya aparecen en el mapa y después en amarillo todo lo que es villas de emergencia...".

Tanto las lecturas del territorio institucionalizadas en el GPS del Comando como las representaciones sociales que los policías producen y reproducen, representan una plataforma desde la cual se "va" a la ciudad, operando de ese modo como un "mapa que precede al territorio, un mapa que proyecta el espacio y que está orientado por las pertenencias sociales y culturales de los actores" (Reguillo, 2008: 72). El territorio se va conformando, de ese modo, como un espacio geográfico culturalmente modelado (Barabas, 2005), presuponiendo la modelación cultural del mismo, la constitución de límites y fronteras espaciales. De hecho, las formas de simbolización que los policías hacen del territorio suponen la existencia de márgenes que no necesariamente se corresponden con las jurisdicciones policiales. Así es que la acentuación de la presencia o no de villas como elemento que referencia a la jurisdicción, lleva a muchos policías a caracterizar, dentro del abanico de "comisarías de trabajo", determinadas zonas de su jurisdicción como "zona de guerra". En las reiteradas visitas a una comisaría de un conflictivo barrio de la zona noroeste, por ejemplo, fue usual escuchar tanto de parte del comisario como del personal, que "esto es zona de guerra". La siguiente observación es gráfica en tal sentido:

"Esto es Saigón", enfatiza constantemente el comisario. Siguiendo una línea de pensamiento bélico, afirma que no sólo la tierra de las calles y la decrepitud del edificio nos hablarían de que nos encontramos en "zona de guerra". Lo mismo ocurre con respecto a la jurisdicción. La extensión es ya un problema. Pero el hecho de que en ese radio haya ocho villas y un FONAVI, constituye para el comisario una situación sumamente problemática y difícil de manejar. "Esto es la guerra" repite para referirse a las actividades cotidianas de la comisaría. En el mismo sentido, otro comisario de la zona nos dirá respecto de ese barrio que "es bravo... hay zonas en donde 9 de cada 10 son choros...".

La clasificación general de una jurisdicción como céntrica o bien como "de trabajo" -marcada por la presencia de villas fundamentalmente- sobre la base de representaciones sociales y también en algún punto de miradas institucionales, trasciende las pertenencias organizacionales que caracterizan a la policía en la provincia de Santa Fe, conformando de ese modo un núcleo de sentido que implica y fundamenta formas diferenciales del hacer en el trabajo policial. De este modo, 
nos encontramos con una dimensión en la cual las diferentes formas de representar y significar la propia jurisdicción no resultan indiferentes. Las mismas modelan "criterios" policiales desde el momento en que diferentes territorios pueden implicar diferentes formas de trabajo. Esto nos comentaba un suboficial sin perder la referencia en torno a la presencia de villas:

"Por eso te digo, distinto, distinto lugares tienen su manera, o sea uno tiene que adoptar una manera de trabajo en cada lugar que va o sea, no es el mismo en todos lados, porque son todos lados diferentes, o sea eh, qué se yo, una comisaría A que es similar a esta, una comisaría B que creo que hay más asentamientos todavía que en acá, es la mayoría, o sea son... eh la $\mathrm{C}$ que son todos comerciantes, o la $\mathrm{E}$ y la $\mathrm{D}$ que es pleno centro entonces, tenés que tener otro trato, otra forma de hablar, todo, es todo diferente, entonces te tenés que ir adaptando a los lugares...".

Inclusive, la forma de realizar el patrullaje también va a diferir. Los funcionarios del Comando entrevistados son claros al respecto. Durante una charla con dos agentes de una misma dotación, ambos coinciden en plantear que el patrullaje es distinto en el centro con respecto a los barrios de la ciudad. Afirman que la relación con "la gente en los barrios es distinta.... no se puede tener el mismo trato, no se les puede 'solicitar' que se acerquen al móvil". En este sentido, afirman que cuando patrullan en barrios hay que "meterle 'más presión'. No se trataría de estar más atento sino de tener otra firmeza en el trato con la gente".

De esta manera, podemos observar que, en forma coincidente con lo que nos arrojaban los datos cuantitativos relevados, las posibilidades de recurrir al empleo de la fuerza son mayores en jurisdicciones no céntricas y más precisamente en las denominadas "zonas de guerra". De hecho, su misma definición nos resulta indicativa en tal sentido. Es en este contexto que, entendemos, comienza a delinearse la emergencia de fronteras que distinguen entre territorios representados como seguros y otros como peligrosos. ${ }^{13}$

Así fue que durante una charla informal con un oficial de una comisaría barrial, por ejemplo, reiteradamente hizo referencia a lo extenso de la jurisdicción y al hecho de que haya muchas zonas con villas de emergencia. En un mapa de la zona, nos fue marcando los distintos sectores donde hay villa, afirmando lo vital que resulta el conocimiento del recorrido de los pasillos. Sin embargo, durante su relato el énfasis estuvo puesto en una manzana en particular donde hay villa, es un 'refugio de choros', pero se encuentra ubicada en una zona residencial: "si esa manzana estaría, la trasladarían, del otro lado de la avenida sería más fácil la cosa porque tendrían todas las villas juntas y ya sabrían dónde están".

Los conceptos de límites y fronteras usualmente no implican una delimitación rigurosa sino un margen permeable y cambiante. No obstante, en la mirada que los policías hacen sobre el territorio aparece esta diferenciación incluso como un límite físico definido. Así es que resulta un problema, en la representación del territorio, la existencia del lado no previsto de un pequeño "manchón" de villa. Si esa media cuadra de asentamientos estuviera "del otro lado", las tareas de control serían mucho más simples y lineales. Rosario ya no es un pueblo, como esos tantos 
de la pampa húmeda, atravesados por vías de ferrocarril que dividen mundos sociales, sin embargo en nuestra experiencia de campo observamos recurrentemente que cada seccional construye sus propias vías de ferrocarril -avenidas, centros comerciales, arterias principales de ingreso a zonas carenciadas, etc.- que para los policías se constituyen en un elemento que orienta en gran medida su propia práctica.

Junto con el peso de esta clasificación empezamos a entrever que, paralelamente a la delimitación de una territorialidad asentada sobre bases tanto físicas como sociales, el "criterio" para la actuación policial comienza a delinear fronteras simbólicas que discriminan entre quienes forman parte de la sociedad "normal" a defender y quienes no, lo cual pone en cuestión cualquier concepto universal de ciudadanía. En sentido, en una de las primeras charlas con un joven oficial que se encontraba a cargo de una comisaría de la zona sur pero sin grado de comisario aún, se nos planteaba:

"Junto con el otro muchacho que es el subjefe mío, salimos en forma personal, caminando a pie, recorriendo los negocios y casas particulares ita? Golpeamos la puerta, nos presentamos como el jefe, como el subjefe y tratamos de tener una relación de... directa... (...). Hablamos de la gente que ya te digo, la gente bien del barrio ¿ta?, es gente que es totalmente instruida".

Profundizando en este sentido y relacionándolo claramente con la existencia de límites físicos definidos, la disponible ${ }^{14}$ de una comisaría de la zona sur nos manifestaba:

"Un poco de todo tenemos. Media jurisdicción dividida por la villa de emergencia... me entendés. Después tenés, ponele, de la calle A para, para... el oeste, tenés un pueblo medianamente de gente... este... de gente normal. En otra jurisdicción, por ahí, tenés la $\mathrm{F}$ que tenés... eh... gente de... estudio, abogados... por eso, son, según las jurisdicciones es la comisaría que... nosotros acá tenemos las dos cosas (...), tenemos gente de... no sé cómo decirlo... de villa de emergencia y gente medianamente... trabajadora...".

La idea de "servicio a la comunidad" -que fundamenta un tipo ideal de policía muy usual entre los policías de comisarías- comienza de este modo a restringirse sobre la base de esta distinción y las dinámicas de trabajo diferenciales que ella implica. Esto es posible ya que las dinámicas de trabajo cotidianas no expresan aisladamente una conceptualización del territorio en cuestión, sino también, íntimamente relacionada, una clara caracterización de las poblaciones que lo habitan. Durante la entrevista, Carrasco ponía un fuerte énfasis en este aspecto:

"Vos donde tenés FONAVIs o villas de emergencia, tenés doscientos mil expedientes más de juzgados de familia, de situaciones de amparo, de un montón de cosas que en jurisdicciones de gente de clase media o media alta y lo mismo ello te implica trabajo de citaciones o despacho judicial, para que vayas al tribunal por distintos trámites, y ni hablar de la parte penal, de los delitos comunes, entre gente normal de determinado nivel cultural, los delitos comunes de llamarle del puterío de familia, bajan y eso queda 
relegado a los niveles más bajos y de acuerdo a que tan más bajo sean se incrementa el homicidio".

En el mismo sentido, un alto funcionario del Comando nos decía al respecto: "Por más que el territorio sea el mismo, una jurisdicción de la comisaría $\mathrm{X}$ ¿si? Por lo que es el nivel socio-económico cultural, a lo que es una Y, que vos tenés en el mismo espacio del territorio infinidad de FONAVI, donde la cantidad de población supera o está al nivel de lo que es una comisaría $\mathrm{X}$, pero tenés otra idiosincrasia, la $\mathrm{X}$ es otro nivel comparado con la Y. Sí, es la misma población: 300.000 habitantes a lo mejor por cada una, pero la calidad de los habitantes no es lo mismo...".

En las jurisdicciones ubicadas por fuera del centro y del radio que comprende los barrios tradicionalmente habitados por sectores medios y altos, las conceptualizaciones que hacen los funcionarios policiales tanto del territorio como de sus poblaciones, se termina sintetizando en un sentido definido y focalizado de la actividad policial. Los relatos del personal del comando son recurrentes en este sentido: "buscamos siempre en los lados marginales, que sabemos adónde pueden salir, buscamos a veces no encontramos (...). Siempre son los mismos aparte".

"nosotros vivimos todo el día adentro de la villa y no nos llaman de San Martín y Pellegrini... sobre todo villa, pasillo, pasillo (...), la marginalidad de la sociedad, nosotros trabajamos con eso...".

"el robo es siempre en torno a la villa, nosotros sabemos perfecto donde roban no sé... Necochea y Ayolas sabemos que vamos a doblar para Tablada porque sabemos que son de ahí, que van a ir para ahí".

Del mismo modo ocurre con personal de comisarías. Un oficial de una comisaría céntrica profundizaba también en este sentido:

"Por ahí uno en un barrio o en un barrio donde tiene villas de emergencia o fonavis, uno sabe que la... que la mayor cantidad de los delincuentes está ahí".

Por su parte, un viejo comisario, con larga trayectoria en comisarías de los suburbios, nos decía:

"A mi me mandaron a la $\mathrm{X}$ porque consideran que yo soy una persona que me desenvuelvo bien en el sector este, me refiero a que yo en mi jurisdicción tengo 6 villas. Yo estoy considerado un "comisario barrero"".

Desde funcionarios con trayectoria y grados jerárquicos hasta jóvenes recién ingresados en la fuerza, la institución policial toda parece leer constantemente idiosincrasias y "niveles culturales". Precisamente, a lo largo de nuestra experiencia en el campo nos encontramos con que la recurrencia y extensión de dichas lecturas permea los distintos ámbitos de actividad policial. En las diferentes dependencias, las conceptualizaciones en torno tanto del territorio como de la población que lo distinguiría operan como marco situacional que impone al policía un modo de actuar, un modo de actuar que necesariamente debe corresponderse, antes que con normas, reglamentos o protocolos, con el marco de relaciones en el que su práctica se despliega. 
La construcción de estereotipos, categorías y clasificaciones no implica que, necesariamente, las prácticas policiales estén definidas y delimitadas por una lógica de clase. No obstante, en forma coherente con los datos relevados de fuentes periodísticas, entendemos que cumplen un rol fundamental en la orientación de las prácticas policiales sosteniendo un uso discrecional de la fuerza de acuerdo al espacio urbano. Dicha discrecionalidad culmina sintetizándose en una focalización ${ }^{15}$ de las prácticas policiales violentas sobre determinadas poblaciones, siendo víctimas de las mismas fundamentalmente jóvenes ${ }^{16}$ que habitan en barrios marginales de la ciudad.

El contexto de uso discrecional de la fuerza -en forma conjunta con la focalización de la violencia sobre los grupos poblacionales que habitan las zonas consideradas 'críticas' que ella implica- constituyen elementos que problematizan las concepciones tradicionales de ciudadanía, sobre todo la propia de la tradición libera ${ }^{17}$ que la entiende ajena a atravesamientos sociales y culturales.

En esta línea, Roberto Kant de Lima (2004) problematiza estas nociones de ciudadanía al pensar las prácticas policiales violentas no como autoritarias sino como jerárquicas, por tratarse de prácticas que obedecen a preceptos de sociedades que ya están estructuradas desigualmente. En el mismo sentido, Dagnino (2004) habla de 'autoritarismo social' para referirse a una matriz cultural vigente en Brasil (y en la mayoría de los países latinoamericanos) que preside la organización jerárquica de las relaciones sociales tanto en el ámbito público como en el privado. Dicha matriz se basa en diferencias de clase, raza y género, estableciendo categorías de personas jerárquicamente dispuestas en sus respectivos "lugares sociales".

Por estas razones, no resulta extraño que gran parte del reclamo de los familiares de las víctimas de violencia policial busque resaltar su condición de ciudadano, en tanto estrategia orientada a denunciar el peso de las diferencias sociales en el uso de la fuerza por parte de la policía. En adelante, nos centraremos en observar cuáles son las manifestaciones de este posicionamiento, sus alcances, su contenido y qué noción de ciudadanía nos están planteando en ese sentido.

\section{¿Qué ciudadanía?}

“...para llegar a algo tuvimos que caminar mucho, en estos dos años, aprendimos que tenemos nuestros derechos. Aprendimos a ponernos firmes" (www.enredando. org, 29/07/05). La ciudadanía implica un posicionamiento, una trayectoria, un devenir. Un proceso de construcción que se desarrolla más allá de las condiciones en que surge. En nuestra experiencia de campo observamos -hecho que nos ocupará esta última parte del artículo- cómo este contexto de uso discrecional de la fuerza y empobrecimiento de derechos, no representa un obstáculo para la emergencia de movimientos sociales que, articulados alrededor de demandas por "justicia" y "esclarecimiento de los hechos" plantean, con un sentido performativo, prácticas novedosas que resignifican las formas de ejercicio de la ciudadanía. En ese marco, como intentaremos demostrar, la noción de ciudadanía se nos va a aparecer reformulada a partir de una reconceptualización del lugar social de la víctima asociada 
a su propia condición de ciudadano, en lo que Elizabeth Jelin (1996) denominaría como un proceso de construcción de "ciudadanía desde abajo". Procesos de construcción de ciudadanía que contemplan las maneras en que quienes son definidos formalmente como ciudadanos llevan adelante las prácticas que corresponden a dicha condición, intentando superar la brecha existente entre la formalidad de la ley y la realidad de su aplicación.

En los primeros acercamientos a este campo ya nos topamos con la constitución de los familiares de las víctimas como un sujeto que pretende defender sus propios derechos a partir de conformarse como actor social del proceso. La cristalización más acabada de este proceso se dio con la constitución de la ONG "Padres del Dolor" ${ }^{18}$ Esta agrupación, conformada sobre finales del año 2003, nuclea principalmente a familiares de víctimas de violencia policial ${ }^{19}$ de la zona del Gran Rosario.

Desde un comienzo, esta agrupación conformada por familiares sin ninguna experiencia previa en el campo de la lucha por los derechos humanos, inscribe sus reivindicaciones en una continuidad histórica que la liga con el movimiento de derechos humanos que surge a partir de la última dictadura militar.

"Ojalá dios quiera que todo esto que, que pasó con nuestros hijos sirva para el futuro para que se vayan cambiando algunas cosas. Y las Madres de Plaza de Mayo tuvieron que pasar treinta años para que las escucharan, para que... bueno, hoy por hoy, encontraran algunos nietos y supieran donde ir a prenderle una velita a sus hijos. Treinta años sufriendo y nosotros bueno... creo que también va a ser... pero al final creo que se ve la lucecita"

En su trayectoria realizaron numerosas marchas, recitales e instalaron una carpa durante semanas frente a los Tribunales Provinciales de esta ciudad en reclamo de "justicia”. Con posterioridad, la agrupación incorporará a familiares de víctimas de violencia no institucional, lo cual terminará generando tensiones en su seno.

"Después eso se fue dividiendo, se fue dividiendo, bueno, por el tema de que se le daba un poco más de, de difusión a los 'gatillo fácil' ¿viste? y a los que eran más resonantes, y bueno... y eso por ahí... y algunas mamás que no soportaron la presión. Después se fue decayendo, pero bueno, las que quedamos seguimos peleando, seguimos de pie, hasta el día de hoy en que la agrupación sigue operando. Más a... más quieta pero sigue operando".

Así, en la actualidad, la agrupación pervive y lo hace con un marcado carácter local. Este carácter fue sostenido por sus miembros a pesar de los distintos intentos de regionalizar su organización, ya sea a través de organismos estatales provinciales y nacionales o de otros movimientos sociales afines en la problemática pero de carácter nacional.

Los enfoques clásicos elaborados alrededor de la teoría de la acción colectiva han procurado brindar distintas explicaciones en torno a los fundamentos (o los elementos fundantes) de las formas de la acción colectiva: Charles Tilly (2000) se concentró en los procesos políticos particulares, las motivaciones individuales, las oportunidades, los intereses y el repertorio propio de los actos de protesta, mientras Sidney Tarrow (1997) puso el foco sobre las oportunidades políticas que se le presentan a colectivos que comparten objetivos comunes. En dichos enfoques, 
siguiendo en esto a Virginia Manzano, "el desarrollo de una mirada exclusivamente centrada en la acción no introdujo al actor sino que produjo la escisión de la acción respecto de los actores y de sus contextos históricos y cotidianos de vida" (2007: 13).

Recuperar el contexto cotidiano de vida asociado a la constitución de los actores implica -en nuestro caso donde son agrupados principalmente padres y madresobservar las formas de legitimidad puestas en juego a partir de que el reclamo se funda en lazos de sangre. La centralidad que asume la categoría de familiar y los vínculos de parentesco en este tipo de movimientos ya ha sido señalada por Pita (2010) y Fernández y Patallo (2008). Asumiendo esta centralidad, los familiares no reaccionan al modo pensado por los clásicos de la teoría de la acción colectiva, respondiendo a procesos políticos, repertorios, motivaciones, intereses u oportunidades; sino que lo hacen casi como una gens (Morgan, 1993) o clan (RadcliffeBrown, 1986) que denuncia y hace público que uno de sus miembros ha sido vulnerado en sus derechos.

"Yo cuando dejo a mi hijo en el cementerio y llego a mi casa... eh.... me desperté y dije 'no, yo tengo que hacer algo, a mí no me pueden venir a arrebatar un hijo así porque sí"

"Mi hijo tenía tantos derechos como él, a defenderse, mi hijo tenía derechos a la justicia"

"Ojalá dios quiera que todo esto que, que pasó con nuestros hijos sirva para el futuro para que se vayan cambiando algunas cosas".

La metáfora consistente en pensar esta reacción como propia de gentes o clanes apunta a resaltar que la forma que asume la acción colectiva se articula principalmente alrededor de la pertenencia de la víctima a una comunidad de parentesco. Así es que las primeras apelaciones a la ciudadanía se van a cimentar sobre su núcleo de identificaciones familiares y cotidianas. En este sentido, en el relato de las madres que conformaron esta agrupación pudimos observar un claro planteo orientado a recuperar su condición de ciudadanía ligada en forma directa con la experiencia sufrida ${ }^{20}$ :

"No era parte. No era querellante, digamos, para participar. Y ¿por qué yo tengo que hacer un juicio al estado, más allá de eso, vamos a suponer, por qué yo tengo que ser parte querellante a través de un juicio, este... eh... a la provincia, para saber y meterme en el expediente? Si yo quiero saber cómo, cómo va a pagar este desgraciado que me arrebató a mi hijo. Yo no estoy pidiendo que me den un arma e ir yo y pegarle un tiro en la cabeza. No. Yo estoy pidiendo que me digan cómo va a pagar este sujeto por lo que hizo, nada más. Yo creo que tengo, es mi derecho como madre y como ciudadana también".

El lugar desde el que se habla es el de "la madre" pero también el de "la ciudadana". Una condición de ciudadanía que, en sus primeras expresiones, se ve mancillada por el accionar de un sujeto, no de una institución. No obstante, ello no inhabilita el desarrollo de un vínculo estrecho entre la experiencia sufrida, las posibilidades de recuperación de su ciudadanía y su conformación como un actor 
social. El mismo vuelve evidente la imposibilidad de pensar el desarrollo de la ciudadanía en forma aislada o escindida del actor y las acciones que la sostienen:

"Mi hijo tenía tantos derechos como él, a defenderse, mi hijo tenía derechos a la justicia. Se fueron, fueron cambiando ellos también muchas cosas. Entonces, nosotros llegamos a la, a la Corte Suprema con, con, con la agrupación. Y en la Corte Suprema fue donde empezaron a bajar líneas y si no... 'denles respuestas a esta gente porque no se van... estos están decididos a quedarse'. Ahí fue donde empezaron a cambiar un poco la, la... hoy por hoy vamos... somos de la agrupación y... ‘qué expediente quieren ver?"”.

El lugar desde el que empieza este recorrido es el de un sujeto lesionado en sus derechos, en disputa con un "otro" claramente identificado que los habría conculcado. Ahora, como podemos empezar a observar con esta última cita, es desde la relación asimétrica con el sujeto que vulnera derechos que la constitución como actor social va a ir decantando en una relación, de carácter mucho más general, con las instituciones del Estado. En este sentido, otra madre planteaba: “... no conocía ninguna, lo que era, lo que era Tribunales. Digamos, de ir a enfrentarme a un juez, a un fiscal. No, no sabía. No, no... no tenía ni idea a dónde tenía que ir. Y fui aprendiendo. No sé, con ayuda de los docentes del colegio donde concurría mi hijo. $\mathrm{Y}$ en la primera semana, cuando fue el primer jueves que se cumplió la fecha, hicimos una primera marcha. Ahí conocí a Gladis y después ya me integré al, al, al grupito que en ese momento se estaba formando y bueno, después nos hicimos, lamentablemente, después se fueron sumando, sumando, sumando. Cuando nos quisimos dar cuenta teníamos... no sé... más de, de cien casos, digamos, de alrededores, muchísimos".

Progresivamente, y al mismo tiempo en que se van constituyendo como actores colectivos, su exclusión de la ciudadanía pasa a ser referenciada como una problemática que asume un carácter social. La cantidad de casos muestra que ya no se trata de un sujeto aislado, sino que el problema evidentemente constituye una problemática social. En este sentido, otra madre nos decía:

"Yo digo que, desgraciadamente, aprendimos mucho. Aprendimos mucho a nivel judicial cómo manifestarnos o con quién hablar y por ahí te sirve para, para aconsejar a otros papás que empiezan en esto".

De este modo, la progresiva inscripción de los sujetos en un marco de relaciones cada vez más amplio, tal como lo empezamos a observar, hace que el concepto de ciudadanía deba trascender la enumeración estática de los derechos y obligaciones que tendrían aquellos que serían definidos como ciudadanos (enfoque que nos llevaría a la única conclusión del desfasaje entre la norma y los hechos) para poder pensarla como una práctica (Bresser Pereira, 1999). Una práctica que, al igual que los movimientos sociales caracterizados por Dagnino (2004) para el caso de Brasil, plantea una concepción de ciudadanía que no se limita al acceso a derechos ya definidos sino que puede implicar la creación de nuevos a partir de prácticas concretas de sujetos sociales activos que luchan por su concreción. 
En tanto práctica, las formas de construcción de ciudadanía se expresan en múltiples dimensiones articuladas sobre la base de un conjunto de representaciones e identificaciones que, en nuestro caso en particular, buscan problematizar los fundamentos del uso discrecional de la fuerza por parte de la policía. De esta manera, si los usos discrecionales de la fuerza por parte de la policía provincial articulados sobre ciertas nociones de territorio y de peligrosidad/ normalidad, constituyen prácticas que niegan la ciudadanía a determinadas poblaciones, estas respuestas nos están hablando de que la misma condición de ciudadanía ahora se ha convertido en "objeto de disputa". Un concepto pertinente de ciudadanía que permita dimensionar estas prácticas muy posiblemente lo hallemos en lo que Mouffe (1999) entiende como una ciudadanía democrática radical, en la que el ciudadano no aparece simplemente como el receptor pasivo de derechos específicos y que goza de la protección de la ley. Ya no se trata de un mero status legal sino de la construcción de una identidad política que nace de la identificación con la respublica. Se trata, de este modo, de un tránsito de lo privado a lo público que caracteriza los procesos de construcción de ciudadanía y que ciertamente constituye los cimientos de la experiencia que estamos analizando. ${ }^{21}$

La visibilización que presupone el tránsito del ámbito privado a lo público resulta central ya que logra exponer lo que permanecía oculto y fundamentalmente adjudicar un nombre y apellido a las listas de casos. En ese sentido, en la conformación de la Asociación se llega a contemplar la importancia de cambiar la denominación de determinadas plazas, realizando una reconceptualización al respecto ligada tanto a la memoria de las víctimas de violencia policial como al respeto y defensa de los derechos humanos.

Los lugares (las plazas) escogidos para recordar a las víctimas de prácticas policiales violentas son, al mismo tiempo, aquellos sitios donde dichos jóvenes pasaban gran parte de su tiempo. De este modo, nuevos significados se superponen e intentan validarse en el territorio:

"En el caso de D. fue porque él pertenecía al grupo de... al grupo de jóvenes que le llamábamos en el barrio que surgió a través de... de las maestras del colegio y de mamás y papás de ahí del barrio, de juntar a los chicos, para limpiar esos terrenos baldíos. Bueno, después entre los docentes y los chicos y algunos papás hicimos un proyecto de la plaza. La plaza, el nombre iba a ser "Plaza de la Amistad" y se lo llevó al Concejo. Bueno, la Municipalidad nos hizo, nos hizo el playón para la cancha de... básquet... y los chicos hicieron la, la parte de la cancha, la parte de la placita para los más chiquititos y... bueno después surgió lo de la muerte de D. y los, los compañeros, los amigos del barrio, los docentes... volvieron a... a... hacer otro proyecto para, no para cambiarle el nombre, sino para ponerle... hacerla en memoria de D. la plaza".

Un dato a resaltar es la relevancia que asume el hecho de que el lugar marcado y señalizado sea el mismo en que se trabajaba, esparcía, donde se pasaba el tiempo libre, etc.. No se trata de cualquier lugar, como un mojón de memoria arbitrario, 
sino de una resignificación de los sitios representativos de su cotidianeidad interrumpida. En otro caso, lo mismo sucede:

"Y hablando con los amigos, siempre se juntaba G. en lo que llamaban antes la plaza de la juventud que era... ahí... y bueno de ahí salió el tema de la plaza, pero todas las cosas públicas que hemos hecho esa era la intención, la idea, de que conocieran el caso, que la gente pregunte, de que se supiera realmente cómo había sido".

Como vemos, el territorio como un espacio que expresa sentidos y la consecuente disputa por la apropiación simbólica del mismo, pasa a ocupar un lugar central en estas formas de lucha por la ciudadanía. Así, si bien las prácticas policiales violentas se focalizaban sobre determinadas áreas consideradas "peligrosas", ahora asistimos, por oposición, a una reconceptualización del espacio público que aparece ligado tanto a su ocupación por los pobladores del barrio como a la memoria colectiva.

Puntualmente, en los fundamentos de uno de los proyectos de ordenanza impulsados por la agrupación aparece la necesidad de que los espacios públicos "deben tender a cumplir un rol tanto de recreación y esparcimiento como así también educativo y de recordación" y "que es suficientemente conocida la importancia de mantener viva esta memoria colectiva para impedir que hechos violatorios de los derechos humanos vuelvan a repetirse" (Ordenanza 7850, Municipalidad de Rosario); mientras que en otro se destaca que la iniciativa obedece a que un "grupo de adolescentes, al cual se unieron padres y demás vecinos interesados en participar, comenzaron a trabajar incansablemente por un objetivo en común: convertir el inmenso basural en un espacio apto para el encuentro, la recreación, las actividades culturales, deportivas y de esparcimiento" (Ordenanza 7856, Municipalidad de Rosario).

Mediante estas inscripciones y señalizaciones el territorio también es convertido en "factor de disputa y de relaciones de poder entre grupos, no sólo en términos de recursos escasos y preciados por los que se compite sino también como construcción simbólica" (Barabas, 2005: 258), en un contexto donde la noción de ciudadanía aparece claramente tensionada. Más bien, el territorio se constituye en uno de los principales tópicos escogidos para librar esta batalla por la ciudadanía. De la mano de la estrategia de la visibilización, la demanda de los familiares no se limita a la exigencia del cumplimiento formal de la normativa, ni a la recuperación de un sujeto de derechos. Sus demandas (y sus inscripciones en el espacio público) están planteando una recuperación de su propia identidad -en gran parte negada justamente a partir de la clasificación del territorio y sus poblaciones que cotidianamente hacen los policías- como parte indisociable de su condición de ciudadano.

Esta última faceta, que finalmente se nos termina mostrando como un aspecto central de su noción de ciudadanía, aparece claramente en la revisión de las crónicas policiales de los periódicos locales: en La Capital, encontramos expresiones de familiares de las víctimas como las siguientes: "queremos que limpien el nombre de G. Él no usaba armas, era un chico trabajador" (11/08/02). Misma actitud es reflejada por la crónica de Rosario 12: "Para la familia, es imposible que G. hubiese 
intentado robar nada, ya que era un 'joven estudioso y trabajador' (10/08/02). Ante el periódico El Eslabón la madre de una de las víctimas manifestaba:

"Yo siempre digo que desperté de esa pesadilla recién el día 11. Después vi las noticias que decían que había muerto un delincuente en un enfrentamiento $^{22}$. Ahí tuve mucha bronca, porque encima de que me lo arrancaban de mi vida, lo ensucian de esa forma. Así que empecé a querer hacer algo para aclarar la situación, para que se supiera la verdad (...). Para mí lo importante siempre fue limpiar el nombre de mi hijo. Me alcanza con el hecho de que se supo la verdad y de que, de alguna manera, en esta provincia algo no quedó impune" (23/11/06).

En este sentido, se instala una lucha que va ligada a una recuperación del lugar social de la víctima que resulta evidente en la constante apelación a su nombre ${ }^{23}$, la cual se articula sobre un concepto de ciudadanía que no es concebido como mero estatus, ni como un conjunto cerrado de derechos, sino como un proceso, como un aprendizaje, una práctica y una lucha, donde la centralidad pasa por identificaciones que realzan su condición de sujeto y que procuran, por sobre todas las cosas, volverlo visible.

Entendemos que cabría retomar la noción de ciudadanía en el sentido propuesto por Luis Cardoso de Oliveira en "Honor, dignidad y reciprocidad" (2004), donde el autor, en el marco de analizar el proceso de institucionalización de la ciudadanía desde demandas por derechos a demandas por reconocimiento de identidades, plantea que un reconocimiento pleno de ciudadanía debe contemplar la indignación experimentada por el actor que ve su identidad negada. Por este motivo, Cardoso de Oliveira recurre al análisis del "don" para ejemplificar estos reclamos, en el que, tanto en las lecturas de Mauss como de Malinowski, el cumplimiento de la obligación moral involucrada en esos actos no se agota en la satisfacción de los intereses de las partes, ni en la afirmación de un derecho, sino que implica el reconocimiento del valor del receptor del don. Así, en los casos que analizamos los actores no sólo están preocupados por el reconocimiento del derecho de las víctimas o por el resarcimiento económico correspondiente sino también por reconstruir la identidad de la víctima, "limpiar su nombre". Cabría concluir entonces, con Cardoso de Oliveira, en la importancia de que cuestiones tales como lazo social, identidad y reciprocidad fuesen asociados también a la preocupación por los derechos y la ciudadanía.

\section{Reflexiones finales}

A lo largo del artículo buscamos exponer, en forma relacional, aquellos tópicos vinculados con el problema de la ciudadanía que emergen a partir de hechos de violencia policial. Para ello, observamos por un lado cómo se define discrecionalmente la utilización de la fuerza por parte de la policía provincial y por el otro distintas estrategias de resignificación de la ciudadanía expresadas por los familiares de las víctimas que reaccionan ante este tipo de hechos.

Dicha reflexión fue otorgándole a la disputa por el espacio un sitio privilegiado. Así fue que partimos de considerar sobre todo el papel del territorio en la delimi- 
tación de las posibilidades de utilización de la fuerza en la policía provincial para luego observar su misma incidencia sobre las formas de construcción de ciudadanía entre los familiares, hecho que nos llevó luego a resaltar cómo el mismo territorio pasa a ser considerado un lugar central en la lucha de los familiares en torno a su condición de ciudadanía.

En ese contexto fue que empezamos a entrever que detrás de esta disputa por la ciudadanía y la apropiación simbólica del territorio, se hallaban presente tensiones referidas al lugar social de la víctima. Un lugar social que para determinadas prácticas policiales se ubicaba en torno a la posibilidad de dar muerte, lo que Pita (2010) ha denominado bajo el concepto de "matable" y que, en el discurso de los familiares era reposicionado bajo el concepto de la ciudadanía, "mi hijo tenía tantos derechos como él...".

La riqueza de la experiencia analizada y los múltiples sentidos que son otorgados a la noción de ciudadanía a partir de ella grafican la necesidad de volver la mirada sobre los procesos concretos y observar cómo, situacionalmente, se van construyendo distintas identificaciones que cargan de significado la noción, muchas veces abstracta, de ciudadanía.

En este sentido es que, creemos, adquiere mayor importancia la perspectiva relacional y etnográfica. El enfoque relacional por cuanto visibiliza los distintos actores significativos que intervienen en un problema donde están involucrados tanto procesos de negación de la ciudadanía como procesos de lucha por la misma; mientras que la etnografía por su parte aparece como un abordaje que posibilita profundizar la observación de estas formas particulares de recrear ciudadanía y, de ese modo, constituir una base desde donde concebir este campo no sólo a partir de los derechos establecidos sino también como un campo de fuerzas y un objeto de disputa al mismo tiempo.

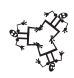

\section{Referencias}

1. Ver Da Matta (1979) y O’ Donnell (1997).

2. En dicha investigación, realizada con el financiamiento provisto por la obtención de las becas doctorales tipos I y II que otorga el Conicet, nos propusimos analizar la forma que asumen las prácticas policiales violentas en la ciudad de Rosario, y el modo en que en el espacio policial se construyen representaciones y significados relativos al uso de la fuerza y al rol social de la policía, en tanto elementos articuladores de un esquema de percepción y valoración constitutivo de alteridades.

3. Distintos investigadores han dado cuenta de esta característica desde diferentes lugares. Sofía Tiscornia $(2004,2005)$ analiza esta situación a partir de concebir la existencia de un centro opaco a la mirada que organiza y legitima el poder de policía, mientras que, en relación con nuestro referente empírico, Sozzo, González y Montero (2010) han mostrado cómo el escaso desarrollo de este tipo de investigaciones se relaciona con los altos niveles de opacidad de las instituciones policiales argentinas, lo que se traduce en una serie de obstáculos prácticos para la realización del trabajo de campo. La misma opacidad ha sido señalada también por Marcelo Sain (2008) con relación a las investigaciones que provienen del mundo académico.

4. Año 2010.

5. Dichas gestiones fueron realizadas en forma conjunta con la Dra. Laura Bianciotto, con quien hicimos las entrevistas a policías que aquí se citan y compartimos nuestro trabajo en el Área de Antropología 
Jurídica de la Escuela de Antropología, Facultad de Humanidades y Artes, UNR y en el Grupo de Estudios sobre Policías y Fuerzas de Seguridad, IDES.

6. En ciencias sociales, la tradición de estudios en torno a la utilización de la fuerza por parte de funcionarios policiales es relativamente reciente, consolidándose en nuestro país sobre finales de la década del '90 del siglo pasado. Esta particularidad, sumada a la ausencia de datos oficiales, da como resultado que contemos con pocos elementos empíricos para afrontar el estudio de esta problemática. Esta situación ha motivado que numerosas investigaciones (CELS, 2010, 2009; Tiscornia, 1999; Programa Delito y Sociedad Informe General período 1998/ 2006, s/r) se orienten hacia la construcción del dato a partir de la información que proviene de las crónicas policiales publicadas en los diarios.

La primacía de la fuente periodística en la investigación en ciencias sociales plantea un problema de importancia en tanto, como bien señala Irene Vasilachis de Gialdino (2005), ante cualquier tipo de texto nos encontramos con modelos interpretativos de la realidad social que no siempre figuran de manera explícita. En este sentido, es usual que las crónicas policiales no sean ajenas a la construcción de interpretaciones de los hechos y que, en general, retomen sin variaciones los discursos del sistema penal, sobre todo el discurso policial (Gómez, 1996).

Este contexto plantea la dificultad y los límites presentes al trabajar con la crónica policial como única fuente. Los mismos ya han sido señalados por Font (1999), Sozzo (2005) y Motto (2009). Sin embargo, ante la ausencia de datos oficiales, el relevamiento de los hechos por la crónica policial se presenta como una fuente de información privilegiada que permite, por lo menos, dimensionar el cuadro de situación y proyectar distintas perspectivas de análisis. En nuestro caso, la fuente analizada fue $L a$ Capital, el periódico de mayor circulación en la ciudad de Rosario.

7. Las muchas limitaciones que presenta la crónica policial de los diarios en tanto fuente de datos nos lleva a considerar como único criterio para su relevamiento a la muerte de la víctima, fundamentados en que la dinámica de producción de la noticia periodística lleva a recoger ineludiblemente, dentro del amplio arco de usos de la fuerza por parte de funcionarios policiales, los hechos que culminan en forma letal; mientras que asume posiciones ambiguas respecto de otras situaciones tales como apremios, abusos, lesiones, etc. Consideramos que ello nos brinda mayor precisión al momento de pensar este cuadro de situación.

8. Incluimos a policías retirados por observar continuidades en su relación con la institución ya sea en términos simbólicos -por el hecho de tener toda una trayectoria dentro de la policía-o en términos operativos, en los numerosos casos en que policías retirados trabajan en empresas de seguridad privada que mantienen vínculos estrechos y cotidianos con la policía provincial.

9. La discrecionalidad también puede ser entendida por referencia a la relación que se establece entre las prácticas concretas y la aplicación de la norma, tal como lo hace, por ejemplo, Marcelo Sain. Sain explica que la misma surge de tres factores principales: "en primer lugar, las leyes y normas que regulan el sistema penal y la seguridad pública de una sociedad conforman preceptos y disposiciones de carácter general que no reflejan ni contemplan la enorme diversidad y complejidad de situaciones, hechos y casos concretos que se producen en la vida social cotidiana y sobre los que esos preceptos y disposiciones deben aplicarse diariamente (...). En segundo término, existe una enorme multiplicidad de leyes, normas y reglamentos regulatorios de la seguridad pública y de los diferentes aspectos que hacen a ésta y al accionar policial. No obstante, esa multiplicidad normativa no engloba todas las situaciones concretas frente a las cuales la policía está obligada a actuar cotidianamente (...). Y, por último, habitualmente se dan condiciones concretas en las intervenciones policiales, casi siempre desenvueltas en situaciones de crisis que requieren respuestas urgentes e inmediatas sobre el mismo terreno, que le imponen a la policía actuante tomar decisiones rápidas que implican la puesta en práctica de ciertas competencias de enjuiciamiento y de iniciativas específicas de la acción policial" (Sain, 2002: 28-29). En este artículo, y sin desconocer este plano, optamos por concentrarnos en los saberes que, trascendiendo la formación profesional y los sentidos reglados del oficio, pueden también fundamentar prácticas discrecionales. En este sentido nos remitimos a lo planteado por Monjardet (2010), cuando hace referencia a la discrecionalidad policial para referirse al proceso de selección que actúa sobre la definición de la tarea policial misma y las actividades a ejecutar y de ese modo orienta y define el trabajo policial, desbordando normas y jerarquías. De este modo, dentro de las múltiples dimensiones que atraviesan las formas en que selectivamente los policías definen su accionar más allá de normas 
y jerarquías, en este artículo ponemos el foco sobre las que provienen de su conceptualización del territorio y las poblaciones que lo habitan.

10. Todos los nombres han sido modificados para respetar el anonimato. Con el mismo sentido, han sido suprimidas también las identificaciones institucionales precisas.

11. Angostas vías de tránsito al interior de este tipo de urbanizaciones.

12. Personal de comisarías abocado a la instrucción de sumarios, etapa administrativa previa a la investigación judicial.

13. Un policía con diez años de trayectoria en el Comando afirmaba: “...en el centro es más que nada es el carterista, lo mecheras, las mecheras, digamos pero, en otras zonas ya hay eh, este robos ya por parte de, con, con tipos de, con otros tipos de armas, depende de las circunstancias, por eso no todas las zonas se trabajan de la misma manera, hay zonas que se trabajan con suma precaución y hay otras zonas que no, ya con un poquito más de, más abierto...".

14. Personal abocado a la recepción, tránsito y archivo de todos los documentos que ingresan a la comisaría.

15. En el Primer Informe del proyecto "Policía, Democracia y Ciudadanía" se muestra claramente cómo los usos de la fuerza por parte de la policía se centran en determinados sectores ciudadanos. En base a una sistematización de los conocimientos que tenían los ciudadanos de una zona de la ciudad de Santa Fe sobre el funcionamiento policial, se determinó que en "...los contactos iniciados por los funcionarios policiales -a diferencia de aquellos iniciados por los ciudadanos-tienen peso las variables de sexo y edad del ciudadano; en dichos encuentros los funcionarios policiales tienen tendencialmente como interlocutor preferencial a varones y jóvenes" y que "los contactos para solicitar documentación predominan entre quienes tienen entre 21 y 40 años, constituyendo el $45,8 \%$ de los contactos iniciados por la policía en esa franja etaria". De este modo, en dicho informe se arriba a la conclusión de que “...estas diferencias de las variables de sexo y edad con respecto a los contactos iniciados por los funcionarios policiales en lo que se refiere a los motivos vinculados a la seguridad frente al delito, podrían ser interpretadas como indicadores del estereotipo de sospechoso/delincuente con el que se guía la actividad policial, especialmente vinculada a la "prevención del delito", esencialmente, joven y masculino" (Programa Delito y Sociedad, 2008).

16. Son numerosos los estudios (CELS, 2005; Vallespir, 2002; Tiscornia, 1999) que remarcan cómo la violencia policial se centra sobre todo en una determinada franja etaria.

17. Si bien es indudable que el liberalismo "contribuyó a la formulación de la idea de una ciudadanía universal basada en la afirmación de que todos los individuos son libres e iguales por nacimiento, también es indudable que redujo la ciudadanía a un mero estatus legal que establece los derechos que el individuo tiene frente al Estado" (Mouffe, 1999: 92). Igualmente, la focalización de los usos de la fuerza por parte de la policía sobre determinadas poblaciones problematiza inclusive los limitados alcances de esta definición, evidenciando la formalidad de dicho estatus para ciertos sectores ciudadanos.

18. Para una historización más detallada del proceso de conformación de esta agrupación, ver Fernández y Patallo (2008).

19. Se trata de los casos comúnmente conocidos como "gatillo fácil". Los mismos representan sólo una parte de los casos relevados en nuestro registro, comprendiendo solamente las ejecuciones extrajudiciales o sumarias en las que están involucrados policías en actividad.

20. En este sentido, Pita (2010) muestra claramente cómo las formas de vivir el hecho de violencia policial adquieren para los familiares - a diferencia ya sea de la mirada policial o bien de la mirada militante- un registro principalmente emocional y afectivo.

21. Pita (2005) también observa esta salida desde el mundo de lo doméstico hacia la arena pública en el caso de las demandas de justicia frente a casos de violencia institucional; salida que es acompañada, igual que en el caso rosarino, por diferentes estrategias de denuncia y visibilización.

22. Distintas investigaciones han dado cuenta cómo este tipo de discursos, si bien reinstalan la figura de la víctima, al mismo tiempo reproducen las valoraciones sociales y policiales en torno al tratamiento del delincuente. En este sentido, lo hegemónico del discurso de la seguridad operaría también en familiares de víctimas del gatillo fácil. Ver: Calzado (s/f.).

23. Pita ha observado, en un sentido semejante, que entre los familiares de las víctimas de violencia policial se produce un intento por restituir humanidad a estas víctimas, las que en principio habían 
sido vistas de acuerdo a las circunstancias de su muerte como "seres matables" (Pita, 2010: 26). Esta operación se hace sobre la base de una resignificación de sus muertes pero también de sus vidas, a través de una multiplicidad de prácticas de denuncia y conmemorativas, tanto individuales como colectivas, que impugnan la forma en que fueron muertos sus familiares.

\section{Bibliografía}

A. BARABAS (2005), "Territorialidad simbólica, santuarios y peregrinaciones", en Actas ler. Congreso Latinoamericano de Antropología, Facultad de Humanidades y Artes, Universidad Nacional de Rosario.

C. BLOJ (2008), Ciudadanía, experiencias deliberativas y nuevas subjetividades políticas en la Argentina post crisis del 2001: Asambleas Barriales y Presupuesto Participativo, Tesis de Doctorado, Instituto Universitario de Investigación José Ortega y Gasset, Madrid, Mimeo.

P. BOURDIEU (1999), "Efectos de lugar", en La miseria del mundo, Madrid, Akal.

P. BOURDIEU y L. WACQUANT (1995), Respuestas por una antropología reflexiva, México, Grijalbo.

L. BRESSER PEREIRA (1999), "Ciudadanía y res pública. La emergencia de los derechos republicanos", en Revista Nueva Sociedad, No 159, Caracas.

M. CALZADO (s/f.), "Elementos para el análisis del tratamiento mediático del caso Blumberg", en Documento de Trabajo $N^{o} 5$, Programa de Antropología Social y Política, Buenos Aires, Flacso.

L. CARDOSO DE OLIVEIRA (2004), "Honor, dignidad y reciprocidad", en Cuadernos de Antropología Social, $\mathrm{N}^{\circ}$ 20, Buenos Aires.

CENTRO DE ESTUDIOS LEGALES Y SOCIALES (2010), Derechos Humanos en Argentina. Informe 2010, Buenos Aires, Siglo Veintiuno Editores.

CENTRO DE ESTUDIOS LEGALES Y SOCIALES (2009), Derechos Humanos en Argentina. Informe 2009, Buenos Aires, Siglo Veintiuno Editores.

CENTRO DE ESTUDIOS LEGALES Y SOCIALES (2005), Derechos Humanos en Argentina, Informe 2005, Buenos Aires, Siglo Veintiuno editores.

E. DAGNINO (2004), "Sociedad Civil, participaçao e cidadania: de que estamos falando?", en D. MATO (coord.), Políticas de Ciudadanía y Sociedad Civil en tiempos de globalización, Caracas, Universidad Central de Venezuela.

R. DA MATTA (1979), Carnavais, Malandros e Herois, Rio de Janeiro, Zahar.G.

DI MARCO, A. BRENER, V. LLOBET, S. MÉNDEZ (2005), Democratización, Ciudadanía y Derechos Humanos. Teoría Y Práctica, UNSAM, Secretaría de Derechos Humanos de la Nación, Buenos Aires, Baudino Ediciones.

E. EVANS-PRITCHARD (1992), Los Nuer, Barcelona, Anagrama.

M. FERNÁNDEZ y M. PATALLO (2008), Análisis del proceso de demanda de justicia de familiares de víctimas de violencia policial. Familiares, jueces y policias en la ciudad de Rosario, Tesis de licenciatura en Antropología, Universidad Nacional de Rosario. Mimeo.

E. FONT (1999), “Transformación en el gobierno de la seguridad: análisis exploratorio de conceptos y tendencias. Su relevancia en Argentina”, en M. SOZZO (comp.), Seguridad urbana. Nuevos problemas, nuevas perspectivas. Santa Fe, Centro de Publicaciones, UNL.

N. GARCÍA CANCLINI (1994), "Identidad cultural frente a los procesos de globalización y regionalización: México y el tratado de libre comercio de América del Norte", en M. AGRIETA y otros (comp.), Las reglas del juego. América Latina, globalización y regionalismo, Buenos Aires, Corregidor.

M. GARRETÓN (2006), "Sociedad Civil y Ciudadanía en la problemática latinoamericana actual", en I. CHERESKY (comp.), Ciudadania, Sociedad Civil y Participación Politica, Buenos Aires, Miño y Dávila.

H. GÓMEZ (1996), "Las noticias policiales en relación a la legitimación de prácticas y discursos institucionales. La "producción" de las noticias y la configuración de discursos hegemónicos", en LEVIS: Laboratório de Estudos das Violencias, CFH, UFSC. Disponible en: http://www.cfh.ufsc.br/ levis/hernan.htm. 
E. JELIN (1996), "La construcción de la ciudadanía: entre la solidaridad y la responsabilidad", en E. JELIN y E. HERSHBERG (coord.), Construir la democracia: derechos humanos, ciudadanía y sociedad en América Latina, Venezuela, Editorial Nueva Sociedad.

E. JELIN (2003), "Los derechos humanos y la memoria de la violencia política y la represión: la construcción de un campo nuevo en las ciencias sociales", en Cuadernos del IDES, Buenos Aires, № 2. R. KANT de LIMA (2004), "Direitos Civis e Direitos Humanos", en Sao Paulo em Perspectiva, San Pablo, $\mathrm{N}^{\mathrm{o}} 18$.

V. MANZANO (2007), 'De La Matanza Obrera a Capital Nacional del Piquete': Etnografia de procesos politicos y cotidianos en contextos de transformación social, Tesis de Doctorado, Buenos Aires, Facultad de Filosofía y Letras, UBA, Mimeo.

T. H. MARSHALL y T. BOTTOMORE (2004), Ciudadanía y clase social, Buenos Aires, Losada.

E. MENÉNDEZ (2010), La parte negada de la cultura. Relativismo, diferencias y racismo, Rosario, Prohistoria Ediciones.

E. MENÉNDEZ (2002), "El malestar actual de la antropología o de la casi imposibilidad de pensar lo ideológico", en Revista de Antropología Social N 11, México, CIESAS.

D. MONJARDET (2010), Lo que hace la policía. Sociología de la fuerza pública, Buenos Aires, Prometeo Libros.

L. MORGAN (1993), La Sociedad Antigua, México, Consejo Nacional para la Cultura y las Artes.

C. MOTTO (2009), "Enfoque metodológico" en A. DAROQUI (comp.), Muertes silenciadas: la eliminación de los 'delincuentes'. Una mirada sobre las prácticas y los discursos de los medios de comunicación, la policía y la justicia, Buenos Aires, Ediciones del Centro Cultural de la Cooperación Floreal Gorini.

C. MOUFFE (1999), El retorno de lo político. Comunidad, ciudadanía, pluralismo, democracia radical, Buenos Aires, Paidós.

G. O’ DONNELL (1997), “¿Y a mí qué mierda me importa? Notas sobre sociabilidad y política en la Argentina y Brasil”, en Contrapuntos. Ensayos escogidos sobre autoritarismo y democratización, Buenos Aires, Paidós.

M. V. PITA (2010), Formas de morir y formas de vivir: el activismo contra la violencia policial, Buenos Aires, Editores del Puerto y CELS.

PROGRAMA DELITO y SOCIEDAD (2008), Experiencias, representaciones y opiniones de los policias de la Provincia de Santa Fe. Primer Informe de la Encuesta Policial 2007, Santa Fe, UNL.

A. RADCLIFFE-BROWN (1986), Estructura y función en la sociedad primitiva, Barcelona, Planeta Agostini.

R. REGUILLO (2008), "Sociabilidad, inseguridad y miedos. Una trilogía para pensar la ciudad contemporánea", en Alteridades, año 18, No 36.

M. SAIN (2008), El leviatán azul, Buenos Aires, Siglo Veintiuno Editores.

M. SAIN (2002), Seguridad, democracia y reforma del sistema policial en la Argentina, Buenos Aires, Fondo de Cultura Económica.

R. SEGATO (2007), La Nación y sus Otros. Raza, etnicidad y diversidad religiosa en tiempos de Politicas de la Identidad, Buenos Aires, Prometeo Libros.

M. SOZZO; G. GONZÁLEZ y A. MONTERO (2010), “¿Reformar la policía? Representaciones y opiniones de los policías en la Provincia de Santa Fe", en M. SOZZO (comp.), Por una sociología crítica del control social. Ensayos en honor a Juan S. Pegoraro, Buenos Aires, Editores del Puerto. M. SOZZO (dir.) (2005), Policía, violencia, democracia. Ensayos sociológicos, Santa Fe, UNL.

S. TARROW (1997), El poder en movimiento. Los movimientos sociales, la acción colectiva y la política, Madrid, Alianza.

C. TILLY (2000), “Acción colectiva”, en Apuntes de investigación del CECYP, año IV, № 6, Buenos Aires.

S. TISCORNIA (2005), "Límites al poder policía. El activismo del derecho internacional de los derechos humanos y el caso Walter Bulacio ante la Corte Interamericana de Derechos Humanos", en S. TISCORNIA y M. PITA (editoras), Derechos humanos, tribunales y policías en Argentina y Brasil. Estudios de antropología jurídica, Buenos Aires, Editorial Antropofagia. 
S. TISCORNIA (1999), "Violencia policial en Capital Federal y Gran Buenos Aires. Cuestiones metodológicas y análisis de datos", en M. SOZZO (comp.), Seguridad urbana. Nuevos problemas, nuevas perspectivas, Santa Fe, Centro de Publicaciones UNL.

S. TISCORNIA (comp.) (2004), Burocracias y violencia. Estudios de antropología jurídica, Buenos Aires, Editorial Antropofagia.

A. VALLESPIR (2002), La Policía que supimos conseguir, Buenos Aires, Planeta.

I. VASILACHIS de GIALDINO (2005), "Mundo del trabajo/ Mundo de la vida", en $7^{\circ}$ Congreso Nacional de Estudios del Trabajo, 10 al 12 de Agosto de 2005, ASET, Buenos Aires.

\section{Fuentes}

Diario La Capital, de la ciudad de Rosario: 11 de Agosto de 2002.

Diario Rosario/12: 10 de Agosto de 2002.

LA JUSTICIA ES UN DERECHO. PADRES DEL DOLOR [en línea] http://www.enredando.org.ar/ noticias_desarrollo.shtml? $\mathrm{x}=23826$

Periódico El Eslabón: 23 de Noviembre de 2006.

Recibido: 20/11/2011. Aceptado: 25/06/2013.

Nicolás Barrera, "La ciudadanía en cuestión: una aproximación etnográfica a los usos policiales de la fuerza y la conformación de colectivos contra la violencia policial". Revista Temas y Debates. ISSN 1666-0714, año 17, número 26, julio-diciembre 2013, pp. 77-101. 